\title{
Molecular analysis to FUT-1,2,3 and ABO genotyping may instead of serological typing to diagnose para-Bombay in Chinese
}

\author{
Haochun Chang ${ }^{1 \Delta}$, Xiaofei $\mathrm{Li}^{2 \Delta}$, Yu-Shiang Lin ${ }^{1}$, Zhiyuan $\mathrm{Xu}^{2}$, Daowang $\mathrm{Fan}^{2}$, Yan Qiu ${ }^{2}$, Tianhong Miao ${ }^{2 *}$ \\ ${ }^{1}$ Department of Clinical Medicine, School of Basic Medical Sciences, Peking University Health Science Center, Beijing 100191, China; \\ ${ }^{2}$ Blood Group Lab, Beijing Red Cross Blood Center, Beijing 100088, China
}

\begin{abstract}
The aim of this study was to evaluate the consistency between serotyping and molecular analysis in Chinese with para-Bombay. The molecular analysis of gene fragments in FUT-1, FUT-2, FUT-3 and ABO genotyping and serotyping were used including a saliva test to examine the $\mathrm{A}, \mathrm{B}, \mathrm{H}$ substance and an absorption elution test to examine the $\mathrm{A}, \mathrm{B}, \mathrm{H}$; and further routine tests including $\mathrm{ABO}, \mathrm{H}$ and Lewis phenotype. From eleven samples with anti-H negative, 10 samples were confirmed with para-Bombay by sequencing to FUT-1, from which six samples were 547-548delAG, three samples were 880TT deletion, one sample was 35C $>\mathrm{T}$ and one sample was $649 \mathrm{G}>\mathrm{T}$ heterozygous (h7, China) as carrier. The sequencing to FUT-2 confirmed $357 \mathrm{C}>\mathrm{T}$ in 11 samples, meaning $\mathrm{H}$, A and B substance was secreted in saliva except for one sample which occurred 385A $>\mathrm{T}$ (I129F) heterozygous, which is a weak secretor. The FUT-3 sequence result demonstrated four samples with heterozygous mutations to 59T>G (L20R) combined with $508 \mathrm{G}>\mathrm{A}(\mathrm{G} 170 \mathrm{~S})$ and seven samples without mutations in FUT-3 gene fragment same as reference. The consistency between sequencing with FUT-1/FUT-2 and serotyping by anti-H reported an identical result, except for one sample, which interestingly showed the $\mathrm{H} / \mathrm{h} 7$ carrier with serotyping negative to anti-H. The result of sequencing with FUT-2/FUT-3 and Lewis phenotyping also reported a complete consistency. The saliva test to A, B, H substance and absorption elution test examining the A, B, H antigens on the surface of red blood cells completely matched the ABO exon 6, 7 sequence results. The sequencing of FUT-1, FUT-2, FUT-3 and ABO exon 6, 7 may become a useful tool to confirm the para-Bombay blood type.
\end{abstract}

Keywords: para-Bombay, FUT-1, FUT-2, FUT-3, ABO blood group

\section{INTRODUCTION}

The $\mathrm{ABO}, \mathrm{H}$ and Lewis blood group antigens are based on a common molecular mechanism, including fucosyltransferase-1(FUT-1). FUT-2, FUT-3. FUT-1 forms an $\mathrm{H}$ antigen on the red blood cell (RBC) membrane and FUT -2 regulates the $\mathrm{H}$ antigen secreted to saliva ${ }^{[1]}$. Lewis phenotype is produced by FUT-

\footnotetext{
*Correspondence to: Tianhong Miao, Blood Group Lab, Beijing Red Cross Blood Center, Beijing, 100088, China. TEL: +86-10-82807272; E-mail: tianhongm@163.com.

${ }^{\Delta}$ These authors contributed equally to this work.
}

2 and FUT $-3^{[2]}$. The phenotype of Le( $\left(\mathrm{a}^{-}{ }^{-}\right)$consists of FUT-3 non-expressed Lewis antigens, Le $\left(\mathrm{a}^{-} \mathrm{b}^{+}\right)$consists of FUT-3 expressed Lewis antigens and FUT2 is a secreted gene, and $\mathrm{Le}\left(\mathrm{a}^{+} \mathrm{b}^{-}\right)$in contrast consists of FUT-3 expressed Lewis antigens and FUT-2 is non-secreted gene ${ }^{[3]}$. The phenotype of $\operatorname{Le}\left(\mathrm{a}^{+} \mathrm{b}^{+}\right)$, which only occurs in the Chinese population, consists of FUT-3 expressed Lewis antigen and FUT-2 is a weakly-secreted gene ${ }^{[4-8]}$. The ABO blood group is based on FUT-1 synthesizing the $\mathrm{H}$ antigen as a precursor and $\mathrm{A}$ transferase or $\mathrm{B}$ transferase to form $\mathrm{ABO}$ antigens on $\mathrm{H}$ antigen ${ }^{[9]}$.

The para-Bombay blood group expresses much fewer $\mathrm{ABH}$ antigens on the $\mathrm{RBC}$ membrane, with $\mathrm{ABH}$ substances present in the saliva. However, the anti-A/ 
anti-B and saliva proficiency and absorption-elution test easily leads to false positive or false negative results. Patients with a clinical status such as being in coma are unable to get saliva, which is also challenge to para-Bombay identification ${ }^{[10]}$. The aim of this study was to evaluate the consistency between serotyping and molecular analysis in Chinese with para-Bombay. We attempted to use molecular analysis to identify paraBombay and this in turn may also offer more information about para-Bombay.

\section{MATERIALS AND METHODS}

\section{Para-Bombay individual and DNA extraction}

This study collected eleven individuals' EDTA test-tube samples and saliva sent to the Beijing Red Cross Blood Center(BRCBC) Blood Group Laboratory (BGL); 5 samples were from Fujian (southeast China), 4 samples were from Beijing and 2 samples were from Taiwan. DNA was isolated from ethylene diaminetetraacetic acid-anti-coagulated blood using a commercial kit (Prepito DNA Blood 250 Kit, Chemagen, PerkinElmer, Germany) based on magnetic separation on an automated system (Chemagic Prepito, Chemagen, PerkinElmer, Germany).

\section{Serological typing, adsorption-elution test and saliva test}

Monoclonal antibodies of anti-A (Inno-train $\mathrm{GmbH}$, Germany), anti-B (Inno-train GmbH, Germany), and anti-H (Sanquin $\mathrm{GmbH}$, Netherlands) were used for ABO forward blood typing, and Al, B, O cells (Shanghai Hemo Pharmaceuitcal Biological Co., Ltd, China) were used for reverse typing. Lewis monoclonal antibody phenotype was used for the diagnosis of Lea and Leb (Sanquin GmbH, Netherlands). An adsorptionelution test was used to examine A and B antigens on red blood cells and a saliva test (based on the haemagglutination inhibition test) to $\operatorname{detect} \mathrm{A}, \mathrm{B}$ and $\mathrm{H}$ substance. Other procedures such as sample reception, report documentation, and report writing were all based on the regulations and standard procedures specified by the BRCBC blood group laboratory.

\section{Molecular analysis to FUT-1, FUT-2, FUT-3 and $\mathrm{ABO}$ exon 6, 7}

Polymerase chain reaction with sequence primers was performed for the $\mathrm{ABO}, \mathrm{H}$ and Lewis blood group by using $\mathrm{H}$ antigen whole genome kit (FUT-1 whole genome sequence kit, Jiangsu LiBio Biotech, China), Lewis blood group kit (FUT-2/FUT-3 whole genome sequence kit, Jiangsu LiBio Biotech, China) and ABO exon 6,7 sequence kit (Jiangsu LiBio Biotech, China).
Sequencing of PCR purified products was done by Sangon Biotech (Beijing, China) and the results were analyzed using sequence analysis software (Geneious R9, New Zealand). The FUT-1 allele (GenBank No. M35531), FUT-2 allele (GenBank No. U17894), FUT-3 allele (GenBank No. X53578), Al.01.01 allele (GenBank No. AY805750) sequence template were used as reference to analyze and mark the mutations.

\section{RESULTS}

\section{Serotyping and sequence analysis to FUT-1}

For 4 of the 11 individuals, the saliva sample was not available, due to clinical status. We were able to examine the other seven samples by using $\mathrm{H}$ substance to neutralize anti-H. By sequencing the FUT-1 gene fragment, four variant types were identified, including homozygous 547AGdel in six samples, homozygous 880TTdel in three samples, $35 \mathrm{C}>\mathrm{T}$ in one sample and heterozygous $649 \mathrm{G}>\mathrm{T}$ in one sample. All eleven individuals believed to have para-Bombay blood type were able to be examined for polymorphisms in the FUT-1 gene fragment depending on their molecular sequences, and other information was shown on Table 1 and Fig.1.

\section{Serotyping and sequence analysis to $\mathrm{ABO}$ blood group}

The routine forward serotyping couldn't detect A, B, $\mathrm{H}$ antigens except for one patient with $\mathrm{h} 7$ carrier reaction $\mathrm{I}^{+}$with anti-A, or $\mathrm{w}^{+}$with anti-B. The absorptionelution test to examine ABO blood type also demonstrated an indistinguishable result, and the saliva test showed complete concordance to $\mathrm{ABO}$ exon 6 and 7 in seven samples. From sequencing to $\mathrm{ABO}$ exon, there are $\mathrm{A} / \mathrm{O}$ in 3 individuals, $\mathrm{A} / \mathrm{B}$ in 2 individuals and $\mathrm{B} / \mathrm{O}$ in 6 individuals, other details are as shown on Table 1 and Fig.1.

\section{Serotyping and sequence analysis to Lewis blood group}

The Lewis phenotype was $\operatorname{Le}\left(\mathrm{a}^{-} \mathrm{b}^{+}\right)$in our study. Sequencing with FUT-2 revealed Se/Se $357 \mathrm{C}>\mathrm{T}$ (silent mutation) in seven samples, Se $357 \mathrm{C}>\mathrm{T}$ homozygous (silent mutation) in three samples and $\mathrm{Se} /$ Se $357 \mathrm{C}>\mathrm{T}, 385 \mathrm{~A}>\mathrm{T}$ (weak secretor) in one sample. All samples' phenotype presented normal secretion (Table 1, Fig.2). For the FUT-3 sequence result, Le $59 \mathrm{C}>\mathrm{T}$ with $508 \mathrm{~T}>\mathrm{A}$ unexpressed le antigens were detected on the RBC membrane. All subjects in our study expressed Le antigen with alleles Le/Le same as reference in seven samples. The other samples were Le/le59, 508 (Table1, Fig.3). 
Table 1 The forward serotyping, saliva test, phenotype and molecular analysis

\begin{tabular}{|c|c|c|c|c|c|c|c|c|c|c|c|c|c|}
\hline \multirow[b]{2}{*}{ Sample } & \multicolumn{3}{|c|}{$\begin{array}{l}\text { ABO for- } \\
\text { ward typing }\end{array}$} & \multicolumn{2}{|c|}{$\begin{array}{l}\text { Absorption } \\
\text { elution test }\end{array}$} & \multicolumn{3}{|c|}{ Saliva test } & \multirow{2}{*}{$\begin{array}{c}\text { Pheno- } \\
\text { type } \\
\text { Lewis }\end{array}$} & \multicolumn{4}{|c|}{ Molecular analysis } \\
\hline & A & B & $\mathrm{H}$ & A & B & A & B & $\mathrm{H}$ & & FUT-1 & FUT-2 & FUT-3 & $\begin{array}{c}\mathrm{ABO} \text { exon } \\
6,7\end{array}$ \\
\hline 1 & - & - & - & - & - & + & - & + & $\mathrm{a}^{-} \mathrm{b}^{+}$ & 547AGdel/547AGdel & $\mathrm{Se} / \mathrm{Se} 357 \mathrm{C}>\mathrm{T}$ & Le/Le & $\mathrm{A} 101 / 01$ \\
\hline 2 & - & - & - & - & - & - & + & + & $\mathrm{a}^{-} \mathrm{b}^{+}$ & 547AGdel/547AGdel & $\mathrm{Se} 357 \mathrm{C}>\mathrm{T} / \mathrm{Se} 357 \mathrm{C}>\mathrm{T}$ & $\begin{array}{c}\text { Le/le } 59 \mathrm{~T}>\mathrm{G} \\
508 \mathrm{G}>\mathrm{A}\end{array}$ & B101/01 \\
\hline 3 & - & $\mathrm{w}^{+}$ & - & - & $\mathrm{w}^{+}$ & $?$ & $?$ & $?$ & $\mathrm{a}^{-} \mathrm{b}^{+}$ & 547AGdel/547AGdel & $\mathrm{Se} 357 \mathrm{C}>\mathrm{T} / \mathrm{Se} 357 \mathrm{C}>\mathrm{T}$ & $\mathrm{Le} / \mathrm{Le}$ & B101/01 \\
\hline 4 & - & - & - & - & - & - & + & + & $\mathrm{a}^{-} \mathrm{b}^{+}$ & 547AGdel/547AGdel & $\mathrm{Se} / \mathrm{Se} 357 \mathrm{C}>\mathrm{T}$ & $\begin{array}{c}\text { Le/le } 59 \mathrm{~T}>\mathrm{G} \\
508 \mathrm{G}>\mathrm{A}\end{array}$ & B101/02 \\
\hline 5 & - & - & - & - & - & - & + & + & $\mathrm{a}^{-} \mathrm{b}^{+}$ & 547AGdel/547AGdel & $\mathrm{Se} / \mathrm{Se} 357 \mathrm{C}>\mathrm{T}$ & $\mathrm{Le} / \mathrm{Le}$ & B101/01 \\
\hline 6 & - & - & - & - & - & $?$ & $?$ & $?$ & $\mathrm{ab}^{+}$ & 547AGdel/547AGdel & $\mathrm{Se} / \mathrm{Se} 357 \mathrm{C}>\mathrm{T}, 385 \mathrm{~A}>\mathrm{T}$ & Le/Le & $\mathrm{A} 101 / 01$ \\
\hline 7 & - & - & - & - & - & + & + & + & $\mathrm{ab}^{+}$ & 880TTdel/880TTdel & $\mathrm{Se} 357 \mathrm{C}>\mathrm{T} / \mathrm{Se} 357 \mathrm{C}>\mathrm{T}$ & $\mathrm{Le} / \mathrm{Le}$ & B101/02 \\
\hline 8 & - & - & - & - & - & $?$ & $?$ & $?$ & $\mathrm{a}^{-} \mathrm{b}^{+}$ & 880TTdel/880TTdel & $\mathrm{Se} / \mathrm{Se} 357 \mathrm{C}>\mathrm{T}$ & $\begin{array}{c}\text { Le/le } 59 \mathrm{~T}>\mathrm{G} \\
508 \mathrm{G}>\mathrm{A}\end{array}$ & $\begin{array}{l}\mathrm{A} 102 / \\
\mathrm{B} 101\end{array}$ \\
\hline 9 & - & - & - & - & - & + & - & + & $\mathrm{a}^{-} \mathrm{b}^{+}$ & 880TTdel/880TTdel & $\mathrm{Se} / \mathrm{Se} 357 \mathrm{C}>\mathrm{T}$ & $\begin{array}{c}\text { Le/le } 59 \mathrm{~T}>\mathrm{G} \\
508 \mathrm{G}>\mathrm{A}\end{array}$ & A101/01 \\
\hline 10 & - & - & - & - & - & - & + & + & $\mathrm{ab}^{+}$ & $35 \mathrm{C}>\mathrm{T} / 35 \mathrm{C}>\mathrm{T}$ & $\mathrm{Se} / \mathrm{Se} 357 \mathrm{C}>\mathrm{T}$ & $\mathrm{Le} / \mathrm{Le}$ & B101/01 \\
\hline 11 & $1^{+}$ & $\mathrm{w}^{+}$ & - & $\mathrm{w}^{+}$ & $\mathrm{w}^{+}$ & $?$ & $?$ & $?$ & $\mathrm{a}^{-} \mathrm{b}^{+}$ & H/649G>T (h7, China) & $\mathrm{Se} / \mathrm{Se} 357 \mathrm{C}>\mathrm{T}$ & $\mathrm{Le} / \mathrm{Le}$ & $\begin{array}{l}\mathrm{A} 102 / \\
\mathrm{B} 101\end{array}$ \\
\hline
\end{tabular}

Note: ? Saliva test didn't be operated because of patient's unconsciousness.
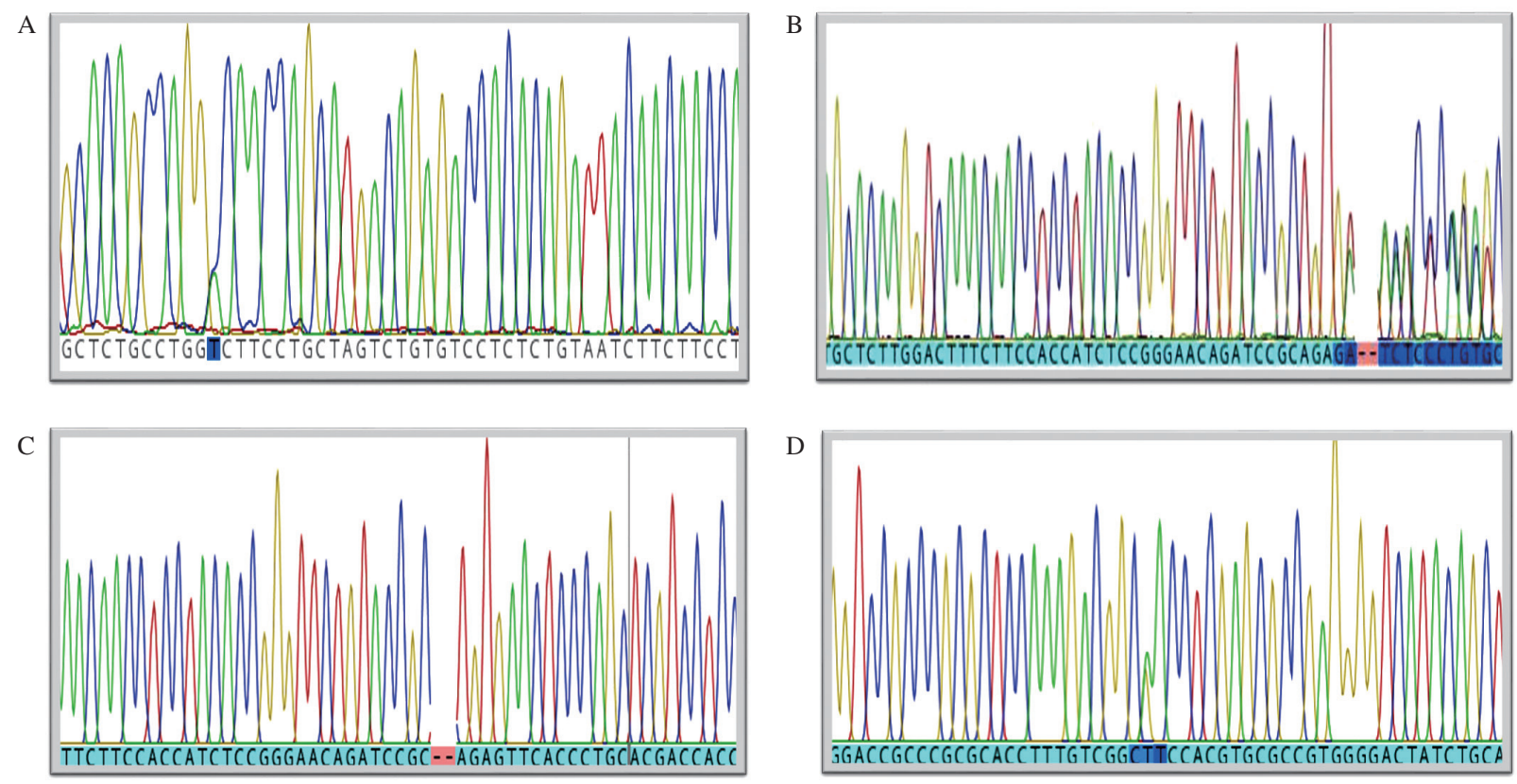

Fig.1. Molecular analysis to FUT-1. A: 35C $>$ T homozygous. B: 547AG deletion homozygous. C: 880TT deletion homozygous. D: 649G $>$ T (h7, China) heterozygous.

\section{Consistency of serotyping and molecular analysis}

The saliva test to examine A, B, H substance was done in concordance with FUT-1, FUT-2, FUT-3 and $\mathrm{ABO}$ exon 6, 7 in seven individuals. For the remaining four individuals, the saliva specimen was not available. The absorption elution test and serotyping test showed indistinguishable results of $\mathrm{ABO}$ typing with the sa- liva test and molecular analysis, however, a serotyping reaction with anti-H is the golden rule to index paraBombay blood type.

\section{DISCUSSION}

Our study used molecular sequence analysis of FUT1, FUT-2, FUT-3 and ABO exon 6, 7 to successfully 

para-Bombay in Chinese, 2017, 1(2)

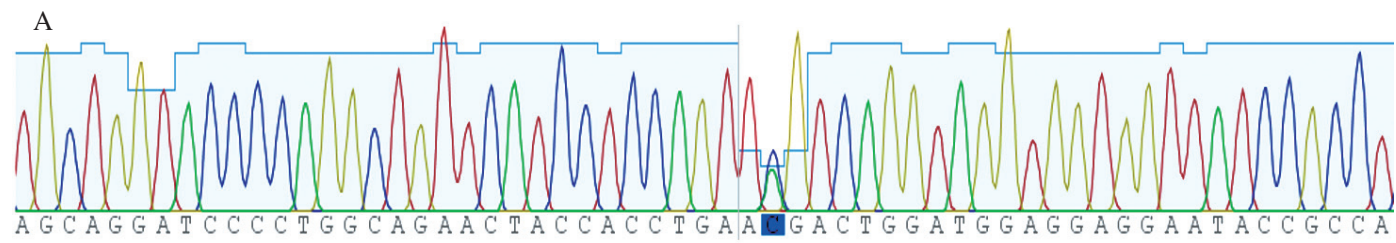

B
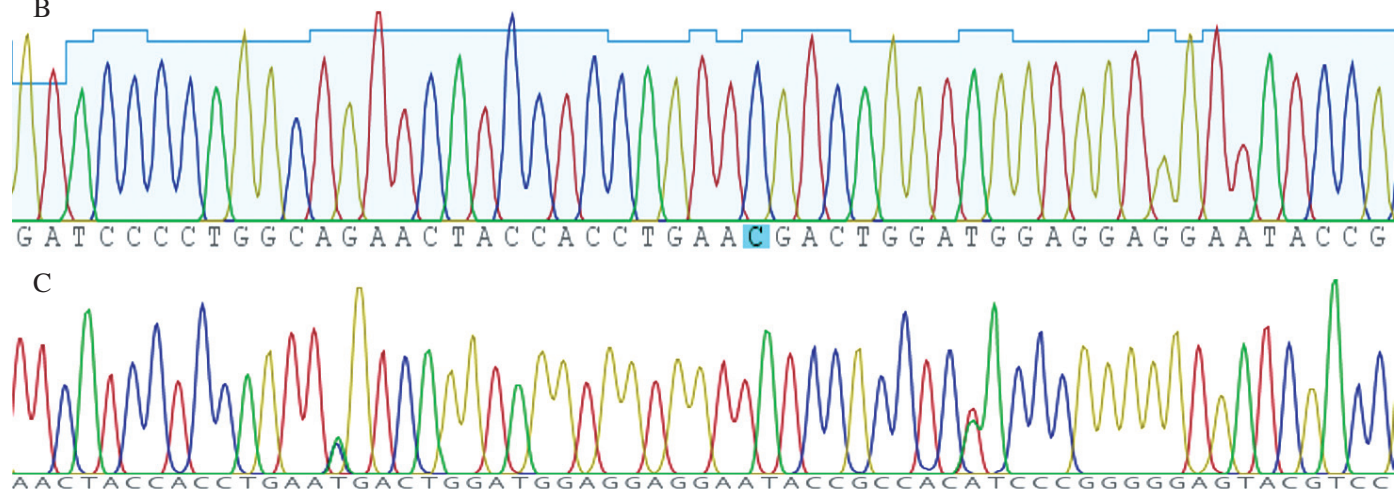

Fig.2. Molecular analysis to FUT-2. A: 357 heterozygous. B: 357 homozygous. C: 547AG deletion homozygous.

A

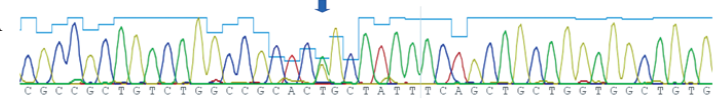

B

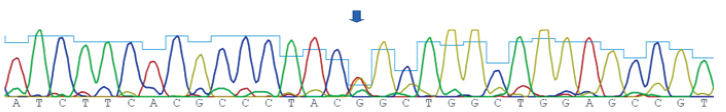

Fig.3. Molecular analysis to FUT-3. A: 59T $>$ G heterozygous. B: 508G $>$ A heterozygous.

identify para-Bombay blood type. The estimated frequency of para-Bombay from the blood donor database is less than $1 / 100,000$ in the north of China, $1 / 8,500$ in Fujian (the Southeast of China) and 1/8,000 in Tai$\mathrm{wan}^{[11]}$. On the other hand, para-Bombay blood type is identified every month in medical centers located in South East Asia. Taking FUT-1 and FUT-2 genomic information could identify Bombay or para-Bombay ${ }^{[12]}$, plus the ABO exon 6, 7 molecule could accurately confirm the $\mathrm{ABO}$ blood type.

Because of the molecular mechanism of synthesizing the Lewis blood group, this phenotype could offer as an assistant tool to diagnose the secretion status through Le $\left(\mathrm{a}^{-} \mathrm{b}^{+}\right)$formed by secretor in FUT2 which is also the most frequent type in the Lewis blood group ${ }^{[1]}$. However, some reasons challenge the Lewis phenotype, including it being a weak secretor only found in Chinese, the monoclonal antibody showed weak reactions with the Lewis phenotype and transfusion interference. We believe molecular analysis of FUT-1, FUT-2 and ABO exon 6, 7 could offer a powerful tool to diagnosis para-Bombay blood type. Hu J. et al. ${ }^{[13]}$ published that ABO genotyping could be used as an assistant tool to diagnose samples with result discrepancies. As one sample in our study was a para-Bombay carrier, we used the $\mathrm{ABO}$ exon 6,7 sequence to identify their $\mathrm{ABO}$ blood type and genomic information. From our study, we found ABO geno- typing may be a faster tool than sequence analysis to diagnose $\mathrm{ABO}$ blood type.

Interestingly, in one individual we observed the FUT-1 sequence was $\mathrm{H} / \mathrm{h} 7$ with serotyping negative reaction with anti-H, with the $\mathrm{ABO}$ exon 6,7 showing normal A101/B101. This patient with cardiovascular disease underwent open heart surgery and excluded hematological disease through peripheral venous blood examination. Although we were unable to find obvious molecular evidence of the cause of para-Bombay, two possible hypotheses in this case were: (1) disease caused weak expression of antigen and (2) A transferase and $\mathrm{B}$ transferase compete emulous reacted with $\mathrm{H}$ antigen and $\mathrm{h} 7$ caused less $\mathrm{H}$ antigen expression on the $\mathrm{RBC}$ membrane. Further study is needed to analyze the molecule and serum examination to confirm if the $\mathrm{h} 7$ carrier indeed has an anti-H negative result.

The advantage of using the experimental molecular tool is that the access to the specimen wasn't limited by the patient's clinical status. The more information from the gene can be obtained and it avoids the bias of human resourced polyclonal anti-A and anti-B and false positive or false negative results caused by staff judgment. Our study offers evidence that molecular analysis of FUT-1, FUT-2, FUT-3 and ABO exon 6, 7 may offer useful information to identify para-Bombay, compared to traditional serotyping including the saliva test and the absorption-elution test. 
Molecular analysis to FUT-1,2,3 and ABO genotyping may instead of serological typing to diagnose 19 para-Bombay in Chinese, 2017, 1(2)

\section{References}

[1] Roback JD. $A A B B$ Technical Manual. 17th edition. Bethesda, $A A B B, 2011$ : 882-5.

[2] Geoff Daniels. Human Blood Groups. 3rd edition. WileyBlackwell. 2013: 25-28, 57-63.

[3] Geoff Daniels. Human Blood Groups. 3rd edition. WileyBlackwell, 2013: 57-63.

[4] Mak KH, Cheng S, Yuen C, et al . Survey of blood groupdistribution among Chinese blood donors in Hong Kong. Vox Sang, 1994; 67 ( Suppl. 2 ).

[5] Broadberry RE, Lin-Chu M.The Lewis blood group system among Chinese in Taiwan.Hum Hered, 1991; 41(5):290-4

[6] Grubb R. Correlation between Lewis blood group and secretor character in man. Nature, 1948; 162: 933.

[7] Yu LC, Yang YH, Broadberry RE, et al. Correlation ofa missense mutation in the human Secretor a 1,2-fucosyltransferase gene with the Lewis $\left(\mathrm{a}^{+} \mathrm{b}^{+}\right)$phenotype: apotential molecular basis for the weak Secretor allele (Sew). Biochem J, 1995; 312 : 329-32 .
[8] Henry S, Mollicone R, Fernandez P, et al.Homozygous expression of a missense mutation at nucleotide 385 in the FUT2 gene associates with the Le $\left(\mathrm{a}^{+} \mathrm{b}^{+}\right)$partial-secretor phenotype in an Indonesian family. Biochem Biophys Res Commun, 1996; 219(3):675-8

[9] Geoff Daniels. Human Blood Groups. 3rd edition. WileyBlackwell, 2013: 21-22.

[10] Roback. JD. AABB Technical Manual. 17th edition. Bethesda, $A A B B, 2011$ : 880-2.

[11] Chi Q, Tang W, Wang C. Molecular genetics analysis and frequency survey of $\mathrm{H}$ deficient phenotype (In Chinese). Chin J Blood Transfusion, 2006; 19(6): 445-8.

[12] Yip SP, Chee KY, Chan PY, et al.Molecular genetic analysis of para-Bombay phenotypes in Chinese: a novel non-functional FUT1 allele is identified.Vox Sang, 2002, 83(3):258-62

[13] Hu J, Nie Z, Gong J. Identification of suspected ABO subtypes by genotyping kits. Asia-Pacific Journal of Blood Types and Genes, 2017,1(1):43-5

(Received 15 May 2017, Revised 30 May 2017, Accepted 09 June 2017) 